\title{
Metode Natural Feature Tracking dan Fast Corner Detection dengan Teknik Virtual Button Pada Aplikasi Sistem Pernafasan Manusia
}

\author{
Rifqi Naufal Senja Pratama ", Fauziah, Ratih Titi Komala Sari \\ Jurusan Informatika, Fakultas Teknologi Komunikasi dan Informatika, Universitas Nasional, Jakarta, Indonesia \\ Email: 1," rifqinauval1106@gmail.com, ${ }^{2}$ Fauziah@civitas.unas.ac.id, ${ }^{3}$ ratih.titi@civitas.unas.ac.id \\ Email Penulis Korespondensi: rifqinauval1106@gmail.com
}

\begin{abstract}
Abstrak- Pada saat ini perkembangan Teknologi Informasi dan komunikasi memiliki perkembangan yang sangat pesat. Seperti pada smartphone, teknologi yang terdapat pada smartphone saat ini memiliki peranan penting bagi aktifitas manusia. Teknologi yang saat ini sedang banyak di implementasikan pada smartphone yaitu Augmented Reality. Augmented reality dapat dimanfaatkan disegala bidang aktifitas manusia, salah satunya pada bidang Pendidikan. Tujuan dari penelitian ini adalah mengembangkan suatu media edukasi tentang organ - organ tubuh pada sistem pernapasan manusia yang interaktif dan mampu dipahami user seperti para pelajar. Pada penelitian ini digunakan 2 metode yairu, Fast Corner Detection dan Metode Natural Feature Tracking untuk membaca suatu marker yang nantinya akan memunculkan suatu informasi dan juga menggunakan Teknik virtual button pada aplikasinya. Pada pengujian menggunakan 5 smartphone. Hasil dari pengujian pada sudut $60^{\circ}$ dan $90^{\circ}$ kelima smartphone dapat mendeteksi marker. Pada pengujian jarak memiliki hasil yang berbeda beda dari yang terkecil memiliki jarak minimal $\pm 70 \mathrm{~cm}$ hingga jarak maksimal $\pm 150 \mathrm{~cm}$. Pada pengujian berdasar intensitas cahaya kelima smartphone dapat mendeteksi marker pada intensitas cahaya diatas 5 lux.
\end{abstract}

Kata Kunci: Augmented Reality; Objek 3D; Implementasi; Edukasi; Teknologi

Abstract-At this time the development of information and communication technology has developed very rapidly. As in smartphones, the technology contained in smartphones today has an important role for human activities. The technology that is currently being implemented on smartphones is Augmented Reality. Augmented reality can be used in all fields of human activity, one of which is in the field of education. The purpose of this research is to develop an educational media about the organs of the human respiratory system that is interactive and can be understood by users such as students. In this study, 2 methods were used, namely Fast Corner Detection and Natural Feature Tracking Methods to read a marker which would later bring up information and also use the virtual button technique in the application. In testing using 5 smartphones. The results of testing at an angle of $60 \mathrm{o}$ and $90 \mathrm{o}$ the five smartphones can detect markers. The distance test has different results from the smallest having a minimum distance of $\pm 70 \mathrm{~cm}$ to a maximum distance of $\pm 150 \mathrm{~cm}$. In tests based on light intensity, the five smartphones can detect markers at light intensities above 5 lux.

Keywords: Augmented Reality; 3D Object; Implementation; Education; Technology

\section{PENDAHULUAN}

Pada saat ini teknologi informasi memiliki perkembangan sangat cepat. Perkembangannya ini memiliki dampak yang sangat penting pada semua bidang aktifitas manusia. Salah satunya pada bidang Pendidikan. Bidang Pendidikan harus menjadi bidang pertama yang merasakan dampat positif dari kemajuan teknologi. Dikarenakan dari Pendidikan inilah akan lahir kreatifitas maupun pengembangan teknologi yang semakin maju [1], [2].

Pada dunia pendidikan saat ini dalam pemberian materi berkaitan tentang sistem pernapasan manusia masih menggunakan patung sebagai bahan contoh. Hal tersebut mempengaruhi anggaran dan juga banyak patung yang tidak terawat. Untuk mengurangi penggunaan patung sebagai bahan objek 3 dimensi yaitu dapat menggunakan teknologi Augmented Reality. Penggunaan teknologi augmented reality dapat mengurangi biaya pengeluaran untuk membeli baranag dalam betuk 3 dimensi. Seperti pada penelitian ini, teknologi augmented reality digunakan untuk media edukasi dan pengenalan organ tubuh yang terdapat pada sistem pernapasan manusia lebih bervariatif dan menyenangkan. Dengan begitu biaya untuk membeli patung organ - organ manusia dapat digunakan untuk kebutuhan lainnya [3].

Pada penelitian berjudul "Augmented Reality Untuk Sistem Pernafasan Pada Manusia " memiliki hasil output sebuah aplikasi augmented reality yang berbasis android. aplikasi ini dalam pembuatannya menggunakan unity untuk membangun sistemnya dan $3 d$ Blender untuk pembuatan objeknya. Aplikasi ini dibuat agar siswa SMP kelas 8 lebih mudah untuk memahami subjek biologis tentang sistem pernapasan dan sirkulasi darah [4] .

Augmented Reality adalah teknologi yang menggabungkan benda dua dimensi atau tiga dimensi yang diimplementasikan ke dalam sebuah ruang lingkup nyata yang kemudian diproyeksikan secara real time [5].

Pernapasan merupakan sebuah peristiwa yang terjadi pada tubuh. Peristiwa tersebut adalah masuknya oksigen kedalam tubuh (inspirasi) melalui organ - organ pada sistem pernapasan. Lalu ketika udara yang masuk sudah mencapai alveolus, terjadi proses pertukaran antara oksigen dan karbon dioksida. Kemudian karbon dioksida akan keluar dari tubuh melalui organ - organ pada sistem pernapasan [6], [7].

Pada sistem pernapasan terdapat beberapa organ vital yaitu hidung, faring, laring, trakea, bronkus, alveolus. Organ - organ tersebut sangat kompleks dan memerlukan pengamatan objek agak dapat dipahami. Sedangan menggunakan alat praga seperti patung atau lilin sebagai contoh pembelajaran memerlukan biaya yg cukup mahal dikarenakan harganya yang tidak murah [8], [9]. 
Salah satu cara untuk mengurangi biaya untuk memperlajari organ - organ pada sistem pernapasan yaitu dengan memanfaatkan teknologi augmented reality sebagai media ajar. Organ - organ pada sistem pernapasan akan divisualisasikan dalam bentuk 3D. Sehingga dapat memberikan perngalaman secara nyata [10], [11].

Penelitian ini dilakukan untuk mengembangankan atau membuat suatu aplikasi yang dapat mempermudah proses pembelajaran. Pembuatan aplikasi ini mengutamakan kemudahan dalam menggunakan aplikasi. sehingga para pengguna seperti pelajar pada jenjang sekolah menengah pertama dan sekolah menengah atas mampu memahami pembelajaran materi sistem pernapasan manusia.

\section{METODOLOGI PENELITIAN}

\subsection{Flowchart Perancangan Aplikasi}

Untuk membangun sebuah aplikasi diperlukan perancangan aplikasi terlebih dahuli. Dengan adanya perancangan aplikasi mempermudah dalam membuat aplikasi yang seperti apa sesuai dengan kebutuhan.

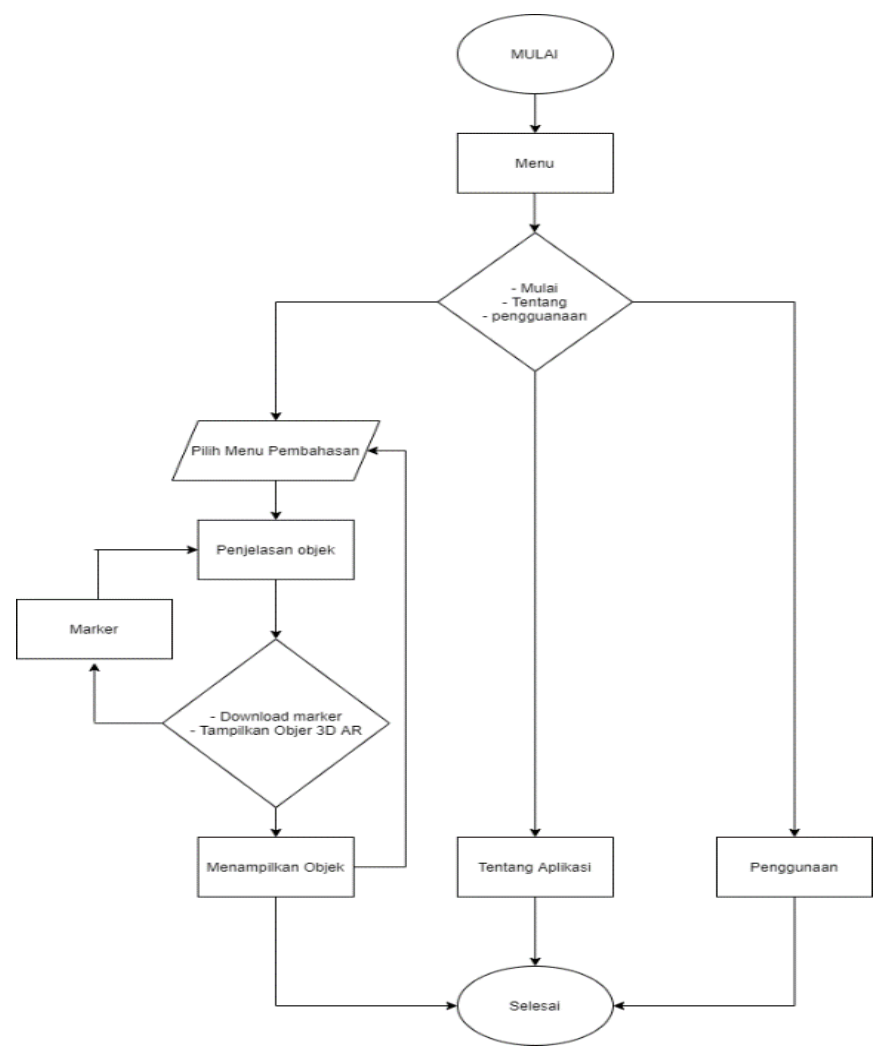

Gambar 1. Flowchart Aplikasi

Pada gambar 1 menjelaskan alur dari aplikasi. Saat aplikasi dijalankan maka tampilan pertama dari aplikasi tersebut adalah menampilkan menu. Pada menu tersebut terdapat suatu pilihan yaitu menu mulai, menu tentang aplikasi, dan menu cara penggunaan. Ketika menu yang dipilih yaitu menu mulai maka proses selanjutnya yaitu menampilkan beberapa menu pembahasan. Ketika memilih salah satu menu maka aplikasi, terdapat pembahasan dari objek yang akan ditampilkan. Terdapat pula dua pilihan yaitu tampilkan dan download marker. Untuk menampilkan objek 3D terlebih dahulu untuk mengambil marker yang tersedia pada pilihan download marker. Kemudian pilih menu tampilkan maka sistem akan melakukan tracking pada marker untuk menampilkan objek 3 dimensi. Pengguna dapat kembali ke menu sebelumnya untuk memilih kembali menu pembahasan yang diinginkan. Ketika menu yang dipilih yaitu tentang aplikasi maka pengguna dapat mengetahui informasi tentang tujuan dari pembuatan aplikasi. Ketika menu yang di pilih yaitu cara penggunaan maka pengguna dapat melihat infromasi penggunaan aplikasi ini agar ketika menjalankan aplikasi ini. Apalikasi dapat berfungsi dengan bai

\subsection{Tahapan Penelitian Dalam Pengembangan Desain Aplikasi}

Pada penelitian ini metode yang digunakan dalam megembangkan aplikasi yaitu metode waterfall. Metode waterfall memiliki rangkaian yang berisi proses yang teratur dan disajikan dalam proses yang terpisah, seperti analisa kebutuhan, penerapan, rancangan, pengujian dan sebagianya. Metode ini terdiri dari beberapa tahapan seperti yang ditunjukkan pada gambar 2 . 


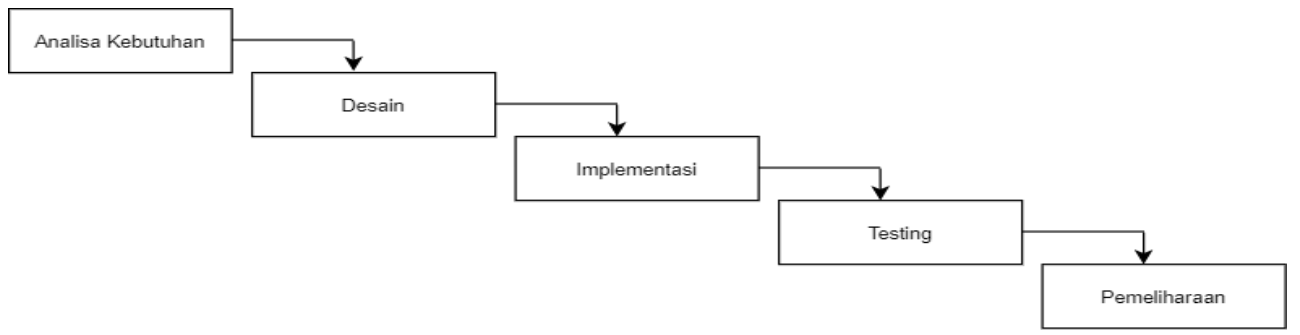

Gambar 2. Tahapan Penelitian

Pada gambar 2 menjelaskan model waterfall yang digunakan dalam proses desain aplikasi dengan penjelasan sebagai berikut :

a. Analisa kebutuhan

Penilitian ini dibuat untuk mengembangkan suatu aplikasi yang mudah digunakan. Seblum melakukan pembuatan pertama yang dibutuhkan adalah Analisa kebutuhan. Pada penilitian ini dibutuhkan beberapa software seperti 3D Blender, Unity 3D, Vuforia Engine, Visual Studio Code. Untuk perangkat keras yang dibutuhkan adalah laptop dan smartphone. Untuk sumber penjelasan tentang sistem pernapasan diambil dari jurnal - jurnal Kesehatan.

b. Desain

Dalam membangun sebuah aplikasi diperlukan desain dari sebuah aplikasi . perancngan desain aplikasi dari augmented reality sismtem pernapasan manusai dilakukan pada software unity. Perancangan aplikasi dilakukan sesuai dengan flowchart aplikasi yang sudat dibuat sebelumnya.

c. Implementasi

Pada tahap ini dilakukannya penerapan dari metode algoritma fast corner dan algoritma detection. Begitu juga penerapan Teknik virtual button pada aplikasi. Penerapan algoritma fast corner dan Metode natural feature tracking pada penelitian ini yaitu membacaya suatu marker yang kemudian akan menampilkan suatu objek 3D dengan penjelasan dari objek tersebut. Teknik Virtual Button digunakan untuk membuat gambar 3D berotasi.

d. Testing

Pengujian dilakukan untuk memeriksa apakah aplikasi berjalan dengan baik dan sesuai dengan metode yang digunaan. Pada tahapan ini aplikasi akan memlaui proses pengujian dengan beberapa penilain seperti :

1. Apakah aplikasi berjalan pada semua jenis perangkat.

2. Pada jarak berapakah aplikasi dapat berjalan dengan baik.

e. Pemeliharaan

Pemeliharaan pada sistem aplikasi sangat diperlukan agar menjaga aplikasi agar dapat berjalan sesuai. Pada tahap ini aplikasi akan dicek kembali apakah terdapat kesalahan yang tidak sesuai atau terdapat sebuah bug pada sistem. Ketika terjadi sesuatu atau akan dikembangi lebih baik lagi aplikasi ini maka tahapan berikut yaitu kembali ketahap awal lagi dengan menganalisa kebutuhan dan Seterus ketahap berikutnya

\subsection{Marker}

Terdapat banyak metode marker yang diganakan pada augmented reality seperti singel marker, multiple marker, markerless, paddle mareker dan virtual marker. Pada pembuatan aplikasi ini salah satu metode marker yang digunakan yaitu single marker. Penggunaan single marker bertujuan untuk memudahkan penggunaan dan pembuatan dikarenakan pada satu marker terdapat satu objek [12], [13].

\subsection{Fast Corner Detection}

Dalam pembuatan aplikasi ini suatu metode algoritma yaitu fast corner detection. algoritma fast corner detection yaitu penentuan titik pusat mendeteksi sudut - sudut dari suatu objek. algoritma ini memiliki tujuan untuk mempercepat waktu proses komputasi secara realtime dengan konsekuensi yang dimiliki yaitu menurunkan tingkat akurasi pendetekasian sudut [14], [15].

\subsection{Natrural Feature Tracking}

Pada pembuatan aplikasi ini juga menggunakan teknik pelacakan gambar berdasarkan bentuk - bentuk yaitu natural feature tracking. Pendeteksian gambar ini melalui sudut - sudut, tepian, maupun gumpalan [16]. Suatu marker yang baik memiliki tekstur yang rumit, memiliki banyak bagian yang terdistribusi secara merata diseluruh gambar sehingga objek - objek yang membentuk gambar memiliki sisi yang jelas [17].

\section{HASIL DAN PEMBAHASAN}

\subsection{Implementasi Fast Corner Detection}

Untuk mengimplexmentasikan algoritma fast corner detection pada apliakasi dapat melalui beberapa proses tahapan ekstraksi pada salah satu objek marker, yaitu: 
ISSN 2614-5278 (media cetak), ISSN 2548-8368 (media online)

Available Online at https://ejurnal.stmik-budidarma.ac.id/index.php/mib DOI 10.30865/mib.v5i3.3067

a. Tahap pertama pada proses fast corner Detection adalah menentukan titik sudut. Warna pada gambar akan dirubah menjadi warna grayscale.

b. Setelah itu, menentukan titik sudut pusat yang akan diberi label p dari input gambar pada posisi awal (x,y). Selanjutnya membuat 16 titik piksel disekeliling titik p dengan radius 3 piksel. Setiap titik piksel diberi label mulai dari 1 hingga 16 searah dengan jarum jam.

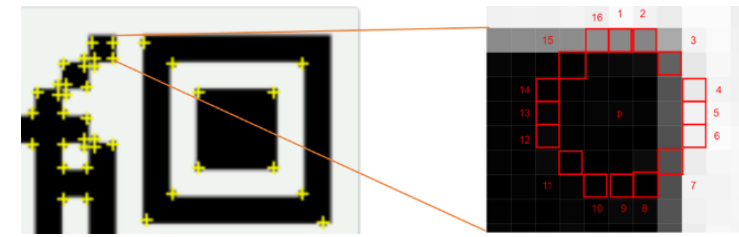

Gambar 3. Menentukan Titik Awal P ( Pusat )

c. Pada fast corner detection untuk mengecualikan yang bukan sudut digunakan tes yang memiliki kemampuan cukup tinggi. Penerapan algoritma ini hanya mengambil 4 piksel dari 16 piksel yang sudah ditektukan

d. Cara untuk menentukan 4 piksel yaitu dengan cara, penentuan titik awal $(n=1)$ terletak pada koordinat $(x p, y p+3)$, lalu titik kedua $(n=2)$ terletak pada koorditat $(x p+3$, yp). kemudian titik ketiga $(n=3)$ dengan koordinat (xp, yp-3). Dan yang terakhir yaitu titik keempat $(n=4)$ dengan koordinat (xp-3, yp).

e. Dalam menentukan sudut $p$ sebagai sudut sebenarnya adalah membandingan nilai intensitas titik sudut $p$ dengan 4 piksel yang berada disekelilingnya yaitu piksel 1, 5, 9, 13. Untuk memenuhi syarat 3 kategori yang ditetapkan algoritma fast corner detection harus memiliki setidaknya 3 titik, yaitu :

$$
S_{p}=\left\{\begin{array}{l}
d, \quad I_{p \rightarrow x} \leq I_{p}-t \text { (Gelap) } \\
s, \quad I_{p}-t<I_{p \rightarrow x}<I_{p}+t \text { (Normal } \\
b, \quad I_{p}+t \leq I_{p \rightarrow x} \quad \text { (Cerah) }
\end{array}\right.
$$

Keterangan :

$S_{p \rightarrow x}$ : Intensitas titik pusat $\mathrm{p}$

$I_{p \rightarrow x}:$ Intensitas piksel $\mathrm{x}$ dengan poin intensitas tetangga ke $-\mathrm{n}$

$\mathrm{t} \quad$ : Treshold

f. Selanjutnya proses repetisi sampai seluruh titik gambar pada marker sudah terkomparasi intensitasnya. Seperti yang ditujukkan pada gambar 4 menampilkan hasil ekstraksi fitur menggunakan algoritma fast corner detection yang terdapat pada vuforia.

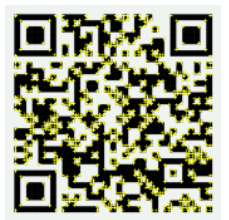

\section{Gambar 4. Ekstraksi Fitur Gambar Pada Marker}

g. Semakin banyak titik (fitur) yang terdapat pada gambar menanadakan jumlah sudut yang terdapat pada gambar dan letak pada koordinat dari titik-titik poin (fitur) ini menentukan keunikan pada marker:

\subsection{Pembuatan Objek 3D}

Salah satu hal utama yang harus dibuat terlebih dahulu yaitu objek 3 dimensi. Objek 3 dimensi akan menjadi output atau hasil yang akan ditampilkan pada aplikasi augmented reality. Objek 3 dimensi akan diletakkan pada marker yang sudah dibuat. Seperti yang ditunjukkan gambar 5 pembuatan objek 3 dimensi ini menggunakan software $3 D$ blender. Proses dibuat dengan pemilihan bagian yaitu sebuah objek bulat dan tabung yang kemdian dibentuk menyerupai paru - paru. Kemudia menambahkan tekstur agar semakin menyerupai paru - paru manusia.

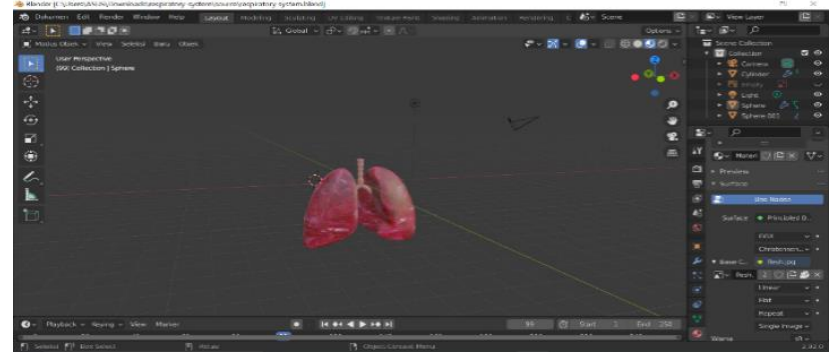

Gambar 5. Model 3D Paru - Paru

Rifqi Naufal Senja Pratama, Copyright (C2021, MIB, Page 1136 
JURNAL MEDIA INFORMATIKA BUDIDARMA

Volume 5, Nomor 3, Juli 2021, Page 1133-1141

ISSN 2614-5278 (media cetak), ISSN 2548-8368 (media online)

Available Online at https://ejurnal.stmik-budidarma.ac.id/index.php/mib DOI 10.30865/mib.v5i3.3067

\subsection{Implementasi GUI ( Graphical User Interface )}

Salah satu tujuan pembuatan aplikasi ini adalah membantu para pelajar agar dapat memahami organ - organ pada sistem pernapasan manusia. Maka dari itu aplikasi dibuat semenarik dan sesederhana mungkin agar para pengguna dengan mudah menggunakan aplikasi. Berikut ini adalah tampilan dari setiap Screen pada aplikasi :

\section{a. Screen Awal}

Screen awal pada aplikasi augmented reality sistem pernapasan manusia menampilkan 2 logo yaitu universitas nasional dan unity. Menampilkan logo awal universitas nasional untuk menandakan aplikasi ini dibuat oleh mahasiswa universitas nasional. Lalu menampilkan logo unity karena pembuatan aplikasi ini dilakukan pada software unity

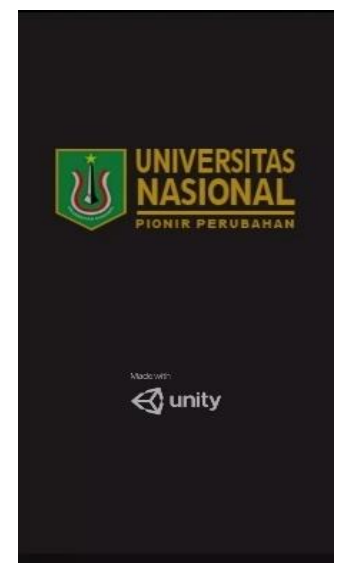

Gambar 6. Screen Awal

\section{b. Menu Utama}

Pada menu utama menampilkan beberapa button yaitu, button mulai, button tentang, button penggunaan.setiap button akan menampilkan setiap screen yang dituju. button mulai akan menampilkan halaman menu - menu pembahasan, button tentang akan menampilkan halaman yang berisikan tentang aplikasi, button penggunaan akan menampilkan halaman yang berisikan cara penggunaan aplikasi. Apabila menekan button tentang maka akan menuju halaman tentang aplikasi. Begitu juga ketika menekan button penggunaan maka akan beralih ke halam cara penggunaan aplikasi

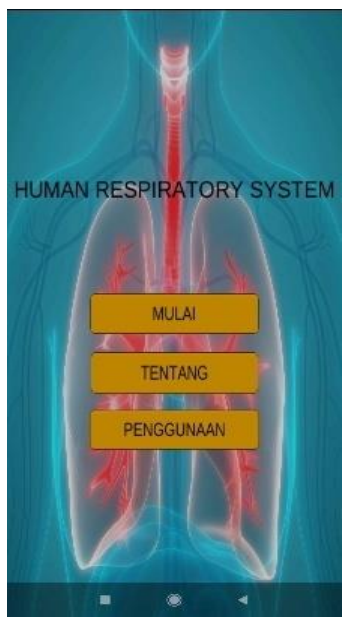

Gambar 7. Menu Utama

\section{c. Menu Pilihan Pembahasan}

Pada halaman ini menampilkan beberapa menu pembahasan yaitu laring, paru - paru, dan diafragma. Ketika memilih menu pembahasan laring maka akan halam akan berganti ke halam pembahasan tentang laring. Begitu juga ketika memiliki menu pembahasan paru - paru dan diafragma maka halam akan berganti ke menu halam pembahasan yang di tuju. 
ISSN 2614-5278 (media cetak), ISSN 2548-8368 (media online)

Available Online at https://ejurnal.stmik-budidarma.ac.id/index.php/mib DOI 10.30865/mib.v5i3.3067

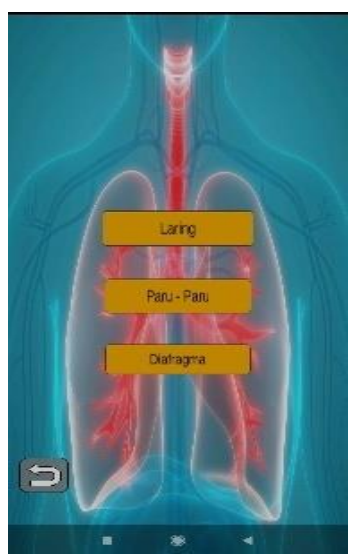

Gambar 8. Menu Pilihan Pembahasan

\section{d. Menu Pembahasan}

Pada halaman ini menampilkan pembahasan tentang organ yang ingin dipahami lebih dalam definisinya. Setiap halam pembahasan memiliki tampilan yang sama yaitu terdapat sebuah penjelasan tentang organ, kemudian button download marker untuk mengambil marker dengan objek yang diinginkan. Dan button tampilkan untuk menampilkan objek 3D.

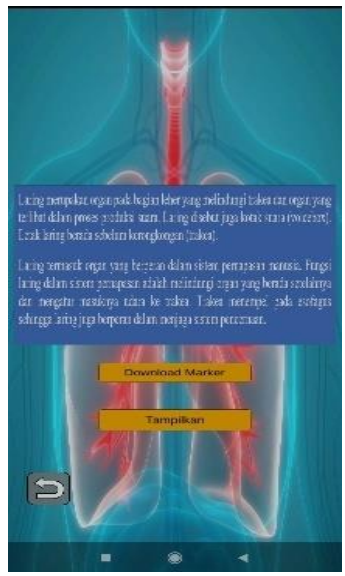

Gambar 9. Halaman Pembahsan

\section{e. Menampilkan Objek}

Pada halaman ini akan menampilkan objek 3 dimensi. Objek 3 dimensi akan tampil setelah sistem memproses marker yang sesuai dengan objek yang diinginkan. Terdapat virtual button rotasi untuk memperlihatkan animasi objek agar berotasi.

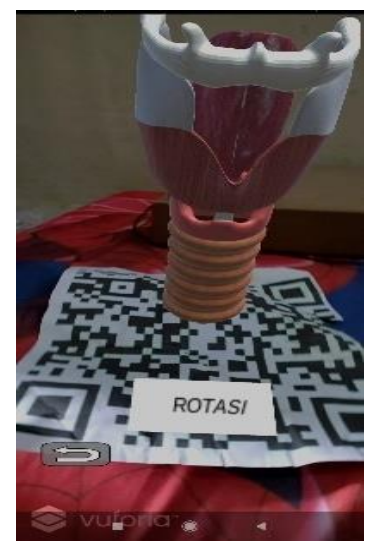

Gambar 10. Menampilkan Objek

\subsection{Perangkat Pengujian}

Pengujian pada aplikasi dilakukan pada versi android dikarenakan sistem pada aplikasi dibuat untuk operating system android. pengujian ini dilakukan pada beberapa tahapan seperti pengujian berdasarkan kemiringan, 
pengujian pada jarak maksimal, pengunjian pada intensitas cahaya, pengujian pada kecepatan waktu respon dalam aplikasi di setiap perangkat. Pengujian ini dilukukan untuk mengetahui perbedaan jalannya aplikasi disetiap perangkat android. Dilakukan pengujian 5 smartphone yang memiliki kualitas yang berbeda pada setiap perangkat.

Tabel 1. Perangkat Pengujian

\begin{tabular}{cc}
\hline Perangkat & Spefikasi android \\
\hline Xiaomi Redmi note 10 & 11 \\
Samsung A20 & 9 \\
Samsung M20 & 8.1 \\
Vivo Y 30 & 10 \\
Vivo Y53 & 6 \\
\hline
\end{tabular}

\subsection{Hasil Pengujian}

Setelah melakukan pengujian dengan 5 smarphone yang berbeda. Mendapatkan hasil dari pengujian sebagai berikut :

1. Pengujian Berdasarkan Sudut Kemiringan

Tabel 2. Pengujian Berdasarkan Kemiringan

\begin{tabular}{cccc}
\hline \multirow{2}{*}{ Perangkat } & & Kemiringan & \\
\cline { 2 - 4 } & $30^{\circ}$ & $60^{\circ}$ & 90 \\
\hline Xiaomi Redmi note 10 & Terdeteksi & Terdeteksi & Terdeteksi \\
Samsung A20 & Terdeteksi & Terdeteksi & Terdeteksi \\
Samsung M20 & Terdeteksi & Terdeteksi & Terdeteksi \\
Vivo Y 30 & Terdeteksi & Terdeteksi & Terdeteksi \\
Vivo Y53 & Tidak Terdeteksi & Terdeteksi & Terdeteksi \\
\hline
\end{tabular}

Hasil dari pengujian berdasarkan kemiringan untuk mendeteksi suatu marker menyatakan bahwa pada kemiringan $30^{\circ}$ hanya smartphone vivo y53 yang tidak dapat mendeteksi marker sehingga objek tidak dapat tampil pada layar aplikasi. Pada kemiringan $60^{\circ}$ dan $90^{\circ}$ kelima smartphone dapat mendetesi marker.

2. Pengujian Berdasarkan Jarak

Tabel 3. Pengujian Berdasarkan Jarak

\begin{tabular}{cc}
\hline Perangkat & Jarak Maksimal \\
\hline Xiaomi Redmi note 10 & $\pm 150 \mathrm{~cm}$ \\
Samsung A20 & $\pm 120 \mathrm{~cm}$ \\
Samsung M20 & $\pm 90 \mathrm{~cm}$ \\
Vivo Y 30 & $\pm 130 \mathrm{~cm}$ \\
Vivo Y53 & $\pm 70 \mathrm{~cm}$ \\
\hline
\end{tabular}

Hasil dari pengujian berdasarkan jarak untuk mendeteksi suatu marker didapatkan hasil sebagai berikut. Pada smartphone Xiaomi Redmi note 10 mampu mendeteksi marker mencapai jarak terjauh maksimal diangka \pm $150 \mathrm{~cm}$. Pada smartphone Samsung A20 mampu mendeteksi marker mencapai jarak terjauh maksimal diangka \pm $120 \mathrm{~cm}$. Pada smartphone Samsung M20 mampu mendeteksi marker mencapai jarak terjauh maksimal diangka \pm $90 \mathrm{~cm}$. Pada smartphone Vivo Y30 mampu mendeteksi marker mencapai jarak terjauh maksimal diangka \pm 130 $\mathrm{cm}$. Pada smartphone Vivo Y53 mampu mendeteksi marker mencapai jarak terjauh maksimal diangka $\pm 70 \mathrm{~cm}$.

3. Pengujian Berdasarkan Intensitas Cahaya

Tabel 4. Pengujian Intensitas Cahaya

\begin{tabular}{ccccc}
\hline & \multicolumn{4}{c}{ Intensitas Cahaya } \\
\cline { 2 - 5 } Perangkat & $\begin{array}{c}\text { Kegelapan } \\
\text { ( O lux })\end{array}$ & $\begin{array}{c}\text { Dalam Ruangan } \\
\text { dengan lampu } \\
\text { ( 5 lux })\end{array}$ & $\begin{array}{c}\text { Ruangan Terkena } \\
\text { Cahaya Matahari } \\
(\text { 114 lux ) }\end{array}$ & $\begin{array}{c}\text { Luar ruangan } \\
(3389 \text { lux) }\end{array}$ \\
\hline Xiaomi Redmi note 10 & TidakTerdeteksi & Terdeteksi & Terdeteksi & Terdeteksi \\
Samsung A20 & Tidak Terdeteksi & Terdeteksi & Terdeteksi & Terdeteksi \\
Samsung M20 & Tidak Terdeteksi & Terdeteksi & Terdeteksi & Terdeteksi \\
Vivo Y 30 & Tidak Terdeteksi & Terdeteksi & Terdeteksi & Terdeteksi \\
Vivo Y53 & Tidak Terdeteksi & Terdeteksi & Terdeteksi & Terdeteksi \\
\hline
\end{tabular}

Hasil dari pengujian berdasarkan intensitas cahaya untuk mendeteksi suatu marker didapatkan hasil sebagai berikut. Pada intensitas cahaya 0 lux ( kegelapan ) kelima perangkat tidak dapat mendeteksi marker. Pada 
intensitas cahaya 5 lux kelima perangkat berhasil mendeteksi marker. Pada intensitas cahaya 114 lux kelima perangkat dengan mudah mendeteksi marker. Pada intensitas cahaya 3389 lux kelima perangkat dengan mudah mendeteksi marker. Untuk apat menghitung cahaya pada suatu ruangan atau diluar ruangan digunakan aplikasi light meter.

4. Pengujian Berdasarkan Kecepatan Waktu Respons

Tabel 5. Pengujian Berdasarkan Kecepatan Waktu Respon

\begin{tabular}{cc}
\hline Perangkat & Respons \\
\hline Xiaomi Redmi note 10 & 1 detik \\
Samsung A20 & 1.4 detik \\
Samsung M20 & 1.5 detik \\
Vivo Y 30 & 1.2 detik \\
Vivo Y53 & 2 detik \\
\hline
\end{tabular}

Hasil dari pengujian berdasarkan kecepatan waktu respons dalam menampilkan objek sebagai berikut. Pada perangkat xiaomi redmi note 10 didapatkan hasil 1 detik untuk menampilkan objek. Pada perangkat samsung a20 didapatkan hasil 1.4 detik untuk menampilkan objek. Pada perangkat samsung m20 didapatkan hasil 1.5 detik untuk menampilkan objek. Pada perangkat vivo y30 didapatkan hasil 1,2 detik untuk menampilkan objek. Pada perangkat vivo y53 didapatkan hasil 2 detik untuk menampilkan objek.

\section{KESIMPULAN}

Pembuatan aplikasi augmented reality sistem pernapasan manusia dibuat menggunakan algoritma fast corner detection dan metode natural features tracking. Penelitian ini dibuat agar mempermudah dalam mempelajari pembuatan aplikasi augmented reality sistem pernapasan. Aplikasi dibuat dengan menggunakan beberapa software yaitu unity, blender $3 D$, dan photoshop. Untuk mengetahui kenyaman dan kemudahan pada aplikasi. Dilakukan beberapa pengujian seperti pengujian berdasarkan kemiringan, pengujian berdasarkan jarak, pengujian berdasarkan intensitas cahaya, dan pengujian berdasarkan kecepatan waktu respon aplikasi. Hasil dari pengujian aplikasi menunjukkan bahwa pada sudut $60^{\circ}$ dan $90^{\circ}$ kelima smartphone dapat mendeteksi marker. Pada pengujian jarak memiliki hasil yang berbeda beda dari yang terkecil memiliki jarak minimal $\pm 70 \mathrm{~cm}$ hingga jarak maksimum $\pm 150 \mathrm{~cm}$. Pada pengujian berdasar intensitas cahaya kelima smartphone dapat mendeteksi marker pada intensitas cahaya diatas 5 lux. Dari hasil pengujian dinyatakan bahwa aplikasi layak untuk digunakan para pelajar sebagai media pembelajaran untuk mengenal tentang sistem pernapasan manusia. Dengan begitu diharapkan para pelajar mampu meningkatkan kembali minat belajarnya dan menjadi penerus bangsa yang hebat dan cerdas.

\section{UCAPAN TERIMAKASIH}

Terima kasih disampaikan kepada dosen pembimbing saya yang sudah ibu Fauziah dan ibu Ratih yang sudah membimbing saya dalam melakukan penelitian ini. Terima kasih juga kepada kedua orang tua saya yang sudah memberikan semangat untuk menyelesaikan penelitian ini.

\section{REFERENCES}

[1] R. D. A. Budiman, "Developing Learning Media Based on Augmented Reality (Ar) To Improve Learning Motivation," JETL (Journal Educ. Teach. Learn., vol. 1, no. 2, p. 89, 2016, doi: 10.26737/jetl.v1i2.45.

[2] L. Hakim, "Pengembangan Media Pembelajaran Pai Berbasis Augmented Reality," Lentera Pendidik. J. Ilmu Tarb. dan Kegur., vol. 21, no. 1, pp. 59-72, 2018, doi: 10.24252/lp.2018v21n1i6.

[3] U. Andayani, B. Siregar, S. Hernina Pulungan, M. F. Syahputra, M. A. Muchtar, and D. Arisandi, "A Visualisation of 3D Lung Anatomy with Augmented Reality as Interactive Medical Learning,” J. Phys. Conf. Ser., vol. 1235, no. 1, 2019, doi: 10.1088/1742-6596/1235/1/012095.

[4] E. L. Amalia and D. Suryani H, “Augmented Reality untuk Sistem Pernafasan pada Manusia," SMARTICS J., vol. 5, no. 2, pp. 55-59, 2019, doi: 10.21067/smartics.v5i2.3390.

[5] C. Habibi and S. T. H. Sulistyanto, "Pengembangan Media Augmented Reality Sebagai Alat Bantu Edukasi Pada Pembelajaran Sistem Pernafasan Manusia,” 2016, [Online]. Available: http://eprints.ums.ac.id/id/eprint/47956.

[6] N. B. Nugraha and S. F. Mahmud, "Implementasi Augmented Reality Pada Aplikasi Sistem Pernapasan Manusia Berbasis Mobile,” J. Mahajana Inf., vol. 5, no. 1, pp. 74-78, 2020.

[7] A. Algifari and T. F. Prasetyo, "Aplikasi Sarana Pendukung Informasi Digital Interaktif Anatomi Sistem Pernapasan Manusia Menggunakan Teknologi Augmented Reality Berbasis Android," Pros. 11th Ind. Res. Work. Natl., pp. 742746, 2020.

[8] A. Lestari, A. Trisnadoli, and M. Dewi, "Analisis Pengembangan Aplikasi Augmented Reality Untuk Pengenalan Organ Pernapasan Manusia,” J. Ris. Komput., vol. 6, no. 4, pp. 429-433, 2019.

[9] S. Aji, E. T. Tosida, and A. Maesya, "Integrasi Simulasi Dalam Augmented Reality Pada Sistem Pernapasan Manusia," Komputasi J. Ilm. Ilmu Komput. dan Mat., vol. 16, no. 1, pp. 213-226, 2019, doi: 10.33751/komputasi.v16i1.1592. 
[10] U. S. Utara, “Universitas Sumatera Utara 4,” pp. 4-16, 2003.

[11] Fatimah, Irawati, and Purnawansyah, "Aplikasi Augmented Reality Media Pembelajaran Organ Tubuh Manusia Untuk SD Kelas 5 Berbasis Android,” Bul. Sist. Inf. dan Teknol. Islam, vol. 1, no. 1, 2020, [Online]. Available: https://www.jurnal.fikom.umi.ac.id/index.php/BUSITI/article/view/518/206.

[12] T. Mulyadi, M. R. H, and A. Amiruddin, "Penerapan Teknologi Augmented Reality Sebagai Sarana Edukasi Perkenalan Alat Musik Dengan Metode Single Marker," J. Inf. Syst. Manag., vol. 1, no. 2, pp. 18-21, 2020, doi: 10.24076/joism.2020v1i2.26.

[13] M. J. Kurniawan et al., "Aplikasi Augmented Reality sistem pernapasan,” Edukasi Dan Penelit. Inform., vol. 1, no. 2, pp. 2-6, 2017.

[14] N. Wahyudi, R. A. Harianto, and E. Setyati, "Augmented Reality Marker Based Tracking Visualisasi Drawing 2D ke dalam Bentuk 3D dengan Metode FAST Corner Detection,” J. Intell. Syst. Comput., vol. 1, no. 1, pp. 9-18, 2019, [Online]. Available: https://jurnal.istts.ac.id/index.php/INSYST/article/view/28.

[15] D. Romdoni et al., "Implementasi Algoritma Fast Corner Detection FAST ( Feature Form Accelerated Segment Test ) dan Augmented Reality untuk Menentukan Keaslian Batik Studi Kasus ( Batik Trusmi ) Cirebon," Uniku, no. 148, pp. 1-6, 2019.

[16] S. Ćuković, M. Gattullo, F. Pankratz, G. Devedžić, E. Carrabba, and K. Baizid, "Marker based vs. natural feature tracking augmented reality visualization of the 3D foot phantom," no. January, 2015.

[17] J. Grafika and N. Kampus, “Analisis Perancangan Permainan Kuartet Dalam,” pp. 6-8, 2015. 